\title{
PROF. DR. İHSAN SÜREYYA SIRMA İLE SÖYLEȘI (05.10.2019/VAN)
}

\section{Söyleşi: Bayram KANARYA*}

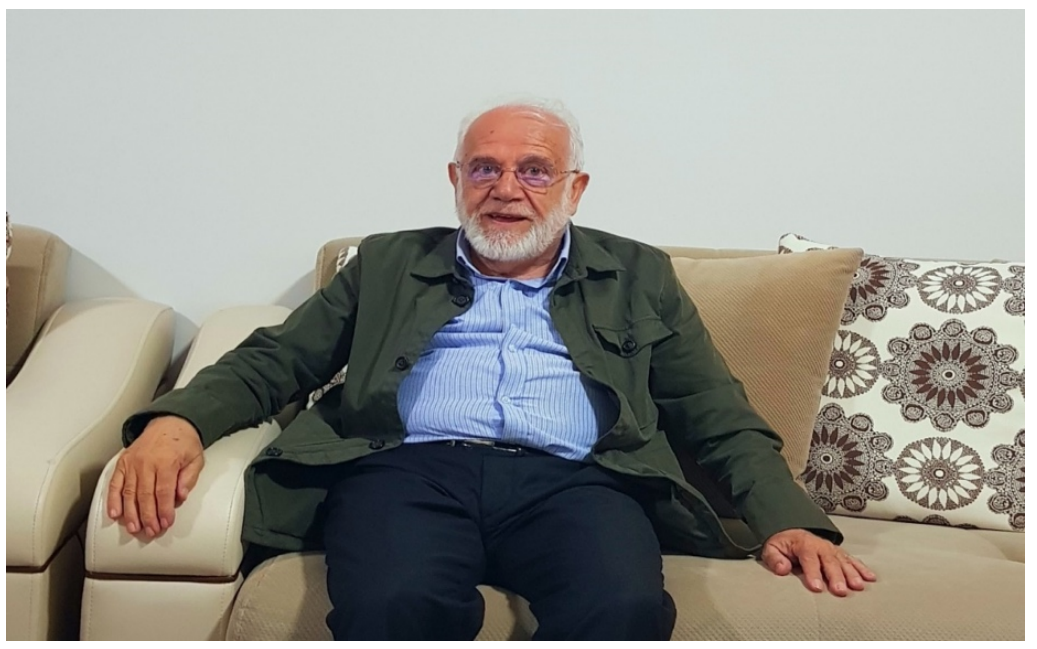

Bayram Kanarya: Sözün başında röportajın gerçekleşmesinde emeği geçen Prof. Dr. Ahmet Erkol ile Halit Bey'e teşekkür ederek başlamak istiyorum. Sayın Hocam e- Şarkiyat İlmi Araştırmalar Dergisi olarak size bir sayı ithaf etmek istiyoruz. Evvela zaman ayırdığınız için teşekkür ederim. Birkaç sorum olacak. Hocam hayat hikâyenizden kısaca bahseder misiniz?

İhsan Süreyya Sırma: Benim bir prensibim var. Kendi hayat hikâyemi ben anlatmıyorum. Adnan Demircan Bey'in hazırlamış olduğu, "Pervari'den Paris'e" adındaki kitaba bakılabilir.

Bayram Kanarya: Hocam rahmetli Tayyip Okiç ve Muhammed Hamidullah hocalardan biraz bahsedebilir misiniz? Nasıl tanıştınız, unutamadığınız anılarınız nelerdir?

İhsan Süreyya Sırma: Bismillahirrahmanirrahim. Evet, rahmetli Tayyib Okiç bendenizin hocasıydı. Ankara İlahiyat Fakültesi'nde öğrenciyken bendenize hocalık yaptı. O zamanlar Türkiye'de bir tek tane olan bu İlâhiyat'ta da hoca diyebileceğimiz sayılı hocalar vard1. Tefsir ve Hadis derslerimize gelen Tayyib Hoca rahmetli, Boşnak asıllıydı. O hocamızın derslerini çok seviyordum. Doktora için Avrupa'ya gittiğimde, bendenize çok önemli bir nasihatta bulunmuştu: "Oğlum Avrupa'da bulunan müsteşriklere dikkat et!"

Article Types / Makale Türü: Interview / Söyleşi

Received / Makale Geliş Tarihi:08.01.2020., Accepted / Kabul Tarihi: 20.03.2020

DOI: https://doi.org/sarkiat.672299

*Van Yüzüncü Y1l Üniversitesi İlahiyat Fakültesi, Temel İslam Bilimleri Bölümü, bayramkanarya@hotmail.com

ORCID ID: https://orcid.org/0000-0002-3525-5789 
Avrupa'dan dönünce de Erzurum'a tayin ettiler. Önce Yüksek İslâm Enstitüsü, sonra da İslâmî İlimler Fakültesinde hoca oldum. O zamanlar maalesef Ankara İlahiyat Fakültesinde hocalık yapmış olan İslâm düşmanı Bahriye Üçok adında bir kadın vardı ki, bu hoca (! )Tayyib Bey Hocamızla çok uğraştı. Askeri Hükumet de onu Senatör yaptı. O askeri dönemlerde, böyle bedavadan senatörlük vardı. İşte askeri devrimin senatörü bu kadın Mecliste Tayyib Bey hocamız aleyhinde konuşmuş, Tayyib Hocamız da çok üzülmüş, hatta "Haymatlos" vatandaş olduğundan bayağı da korkmuştu. Her akşam olduğu gibi mesaiden sonra Tayyib Hoca'ya gider sohbetini dinlerdik. İşte bu olayın olduğu gün yine kendisine gittiğimizde onu çok üzgün gördük.

Rahmetli Hoca Haymatlos (vatansı) olduğu için korkuyordu, memleketi olan Yugoslavya'ya sürülmekten korkuyordu. O zaman Yugoslavya'da, Saraybosna'da komünizm rejimi vardı. Hocamızı teselli için, "Hocam zararı yok, bir şey olmaz. Kadın kendine kendine konuşsun" dedim. Hiçbir zaman kendisinden azar duymadığım Tayyib Hoca bana, "Sus eşek herif!" demez mi!.

Bir hatırasını daha anlatayım. Hocanın daktilo yazacak vakti yoktu. Daha doğrusu yaşlandığından daktilo ile yazamıyor elle yazıyordu. Elle yazdığı makalelerini bendenize verir biz de daktiloya çekerdik. Daktiloya çekilecek makaleyi alınca her zaman şöyle tenbih ederdi: "Bunu götür ve dikkatlice "taper" et!" Taper kelimesi Fransızcadır. Bir gün yine bir makale verdikten sonra beni şöyle uyarmıştı: "Al bunu götür taper et, getir." Sonra da dolaylı olarak beni şu şekilde uyardı: "Şimdi yeni insanlar çıkmış on parmak yazıyorlar. Onlar çok hata yapar; senin gibi iki parmakla yazanlar daha az hata yaparlar. Ben hiç hata yapmamak için tek parmakla yazıyorum!” İşte bazen böyle espriler de yapardı. Hocamızın bir özelliğini daha anlatayım: Rahmetli Tayyib Hoca, aynı zamanda dünya çapında bir ilim adamı olan rahmetli Fuat Sezgin Hocanın da doktora hocasıdır. Buhârî'nin Kaynakları adındaki doktora tezini Tayyib Hocamızın yanında yapmıştı. Böylece rahmetli Fuat Sezgin Hoca ile iki ayrı hocadan ders almıştık: Tayyib Hoca ve Muhammed Hamidullah Hoca!

Doktora için Paris'e gittiğimde, Hamidullah Hoca ile haftada mutlaka iki defa görüşürdük. Bir Cuma günü bir de Pazar günü. Pazar günü saat iki buçukta onun Müslüman Talebe Cemiyeti'nde semineri oluyor, biz de dinliyorduk.

Beş on Müslüman öğrenci, kendi aramızda para toplayıp, Paris’te küçük bir lokal satın almıştık. Hamidullah Hoca da her Pazar günü oraya gelir, saat 14.30 'da seminer yapardı. Bir karlı Pazar gününde lokali süpürme ve sobayı yakma nöbeti bana gelmişti. Lokale saat 14.00 'te gidip lokali süpürdüm ve sobayı yakıp Hoca'yı ve dinleyici arkadaşları beklemeye başladım. Saat ikiyi çeyrek geçe hoca geldi; iki buçukta seminer yapacak. Saat iki buçuk oldu, hiç kimse yok. Üçe çeyrek kala oldu, yine hiç kimse yok. Kendi kendime kimse gelmedi düşüncesiyle, eğilip sobayı söndürmek istedim. Fakat dünyada tanıdı̆̆ım en kibar insan olan Hamidullah Hocam, bana sert bir şekilde,

-Ne yapıyorsun? diye seslendi.

-Hocam dedim; kimse gelmedi, söndüreyim gidelim. Bu cevabım üzerine Hoca geldi ve kulağımdan çekerek, 
-Otur şuraya! dedi.

O kibar insan, elli kişi değil, yüz kişi dinliyormuş gibi seminerini yaptı; bitirdikten sonra da dedi ki:

-Oğlum, bugün burayı kapatırsak bir daha açılmaz!

Sonraki hafta tabi gelmeyen arkadaşları fena haşladım. Böyle prensip sahibi hocalar. Onun için diyorum ki ben bu iki hocamdan çok şey öğrendim. Dakik olmayı Hamidullah Hocam'dan öğrendim.

Bayram Kanarya; Hocam, doktoranızı Fransa'da bitirdikten sonra Türkiye'ye dönüşs sırasında üniversiteye öğretim üyesi olarak atanma sürecinizi biraz anlatır mısınız? Hangi problemlerle karşılaştınız? Neden mezun olduğunuz Ankara İlahiyat değil de Erzurum İlahiyat? Erzurum İlahiyat'tan Sakarya İlahiyata geçişiniz hakkında ne söylersiniz? Sakarya İlahiyat'tan ayrılma sebebiniz neydi efendim?

İhsan Süreyya Sırma; Galiba röportajınızın tamamı bu. Kısaca anlatayım:

Fransa'da doktoramı bitirdikten sonra mezun olduğum Ankara İlahiyat'a gidip hocalarıma:

“Hocalarım, beni Avrupa'ya gönderdiniz; ben de doktor olup geldim. Beni fakülteye alın, hizmet edeyim. İslam tarihi profesörü rahmetli Hüseyin Gazi Yurdaydın Hocam,

-İhsan dedi, kadrom yok; kadro verince seni alacağım! dedi.

O arada sosyolojiden sınav açıld1. Doktora hocam sosyolog olduğundan, iyi bir sosyoloji alt yapım vardı. Açıkta kalmaktansa sosyolojiden sınava gireyim dedim.

Gittik imtihana girdik. Bir tek benim aldığım notlar iyiydi. Sosyoloji hocamız ise başka bir arkadaşa söz vermiş; ama imtihanı ben kazanmıştım. Rahmetli Taplamacı Hoca bir türlü karar veremiyordu. Nihayet, terbiyemi biraz bozarak, "hocam, birimizi seçin de kurtulalım” dedim. Siverekli bu hocamız çok küfürbazdı. Almak istediği arkadaşa, "oğlum" diyor, "hiçbir şey yazmamışsın”. Sonra bana dönüp, "ulan eşek oğlu eşek, sen her sene tatile gelip Siirt'e gidiyorsun neden Ankara'ya gelip elimi öpmedin.” Böyle bir adamdı Taplamacı Hocamız.

Sınıfa geldiğinde mutlaka bir öğrenci "dikkaaat" çeker sonra da Hoca derse girerdi. Diğer hocalarımız gibi Allah ona da rahmet etsin. Böylece her gün git-gel yapıyoruz...En az bir hafta bu git-gel'ler devam etti. Bir defasında dedi ki "ben iyi bir Müslüman olsaydım, istihareye yatardım, o da yok". Sonra da dedi ki "ben bir karar verdim. Notu Sırma aldığı için mecburen onu alacağım. Sana da iki ay sonra bir kadro açacağım." deyip, karar verdi; kararını Dekanlığa bildirdi. Sonra da, "oğlum ben İspanya'ya gidiyorum sana bir oda ayarlanıncaya kadar benim odamda çalış!” Ben de iş başı yapmak için bekliyorum; fakat Dekanlık bir türlü tayinimi yapmıyor! Sonra Dekan Necati Bey beni çağırıp, "İhsan, sen Siirt'e git ve tayin olurunu bekle, sana bildiririz!" dedi. Ben de Siirt'e gidip, saf saf iki ay bekledim. Çünkü Necati Bey, fakülteden benim 
hocamdı; bana yamuk yapacağını aklımın köşesinden bile geçirmezdim. Fakat bazı "meş'ûm ilkeler mülahazasıyla" tayinimi yapmadılar! Meğer ben Siirtliymişim!!!

Bugün ülkemizin Doğusu'nda cereyan eden müessif olayların sebebi, bu gibi “ilkel ilkeler" değil de nedir?

Eylül ayı gelince bir telgrafla Erzurum İmam Hatip Lisesine Dr. öğretmen olarak tayin edildim.

Bir sene öyle geçti. Sıkıntılar çekmedim, diyemem...

Bir sene sonra rahmetli Prof. Dr. Lütfü Ülkümen beni güzel bir imtihandan geçirdikten ve de Şerafettin Gölcük’ten tezkiye aldıktan sonra, Erzurum İslâmî İlimler Fakültesi’ne asistan olarak ald1.

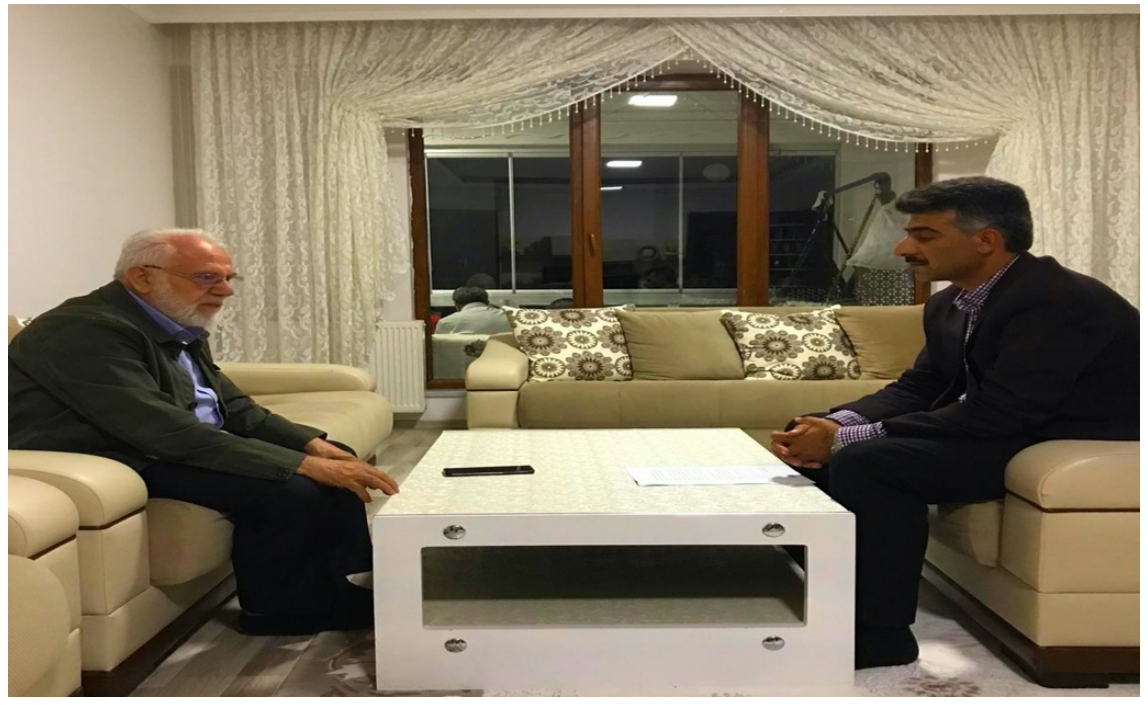

\section{Bayram Kanarya: Hocam Erzurum'da ne kadar görev yaptınız?}

İhsan Süreyya Sırma: Fazla değil yirmi sene görev yaptım. Yirmi seneden sonra Sakarya İlahiyattan beni istediler ve naklen oraya geçtim. O arada rektörlük seçimi yapıld1 ve beni Sakarya'ya istemiş olan Rektör, seçimi büyük bir farkla kazanmasına rağmen, o zamanki YÖK başkanı olan Gürüz, kendi emrinde olacak olan ve çok az oy almış olan Prof. Osman'ı atadı.

O zaman İlahiyat Fakültesi'nin Dekanı, Fetullah'ın has adamı olan ve halen Amerika'da Feto'nun yanına kaçmış olan Prof. Suat Yıldırım'dı. Her zaman yaptıkları gibi, kendi şakirdlerine kopya vererek, fakülteye asistan almak istediler. Ben de, -hoca yokluğundan- bütün jürilerde olduğumdan buna mani oldum. Bunun üzerine Rektörle birleşerek, emirlerinde olan Prof. Cevat Akşit'i de muhakkik (!) tayin ederek, uydurma bir soruşturma ile işime son verdiler. İdare mahkemesinde dava açıp kazanmama rağmen bir daha başlatmadılar! Çünkü artık Feto'nun emrinde olan Prof. Suat ve Prof. Cevat fakülteye hakimdiler!!!!

O zaman Recep Tayyip Erdoğan Bey İstanbul Büyükşehir Belediye Başkanıydı. Bu olayları müteakip "Hocam" dedi "bana danışman olur musun?", “olurum” dedim. Oldum ve iki sene danışmanlık yaptım. Sonra o hapse girdi; ben de Viyana'ya gittim. 
Viyana'da bir Enstitü kurdum ve on sene Viyana'da kaldım. Şimdi hala kurduğum enstitü devam ediyor. Her sene gidiyorum. Benim eserim değil, Müslümanların eseri. Türkiye'ye döndüm. Bu sefer Siirt'e ilahiyat açıldı. Arkadaşların zoruyla ve de öğrencilerim olan Prof.ların raporlarıyla memleketim olan Siirt'e hoca oldum ve Temmuz 2019'da yaştan dolayı emekli oldum. .

Bayram Kanarya: Üniversiteye intisap ettiğiniz yıllarda Türkiye'deki üniversiteler ile doktoranızı yaptığınız Fransa'daki üniversiteleri mukayese etmeniz mümkün müdür?

İhsan Süreyya Sırma: Yok mümkün değil, çünkü bu saatler alır. Türkiye'de rejim nasıl isterse üniversiteler öyle ama Fransa öyle değil. Bu kadar net!.

Bayram Kanarya: Sayın hocam siyer ve hadis ilminin metodolojileri, ayrışan ve birleşen yönleri ile ilgili görüşleriniz nelerdir?

İhsan Süreyya Sırma: Estağfirullah bu beni aşan bir şey. Bir defa hadis konusunda rahmetli Tayib Hoca'nın kitapları var. Muhaddis arkadaşlarımızın var. Siyerde de Hamidullah Hoca'nın var. Ama yine de İslam ve Tarih diye bir kitap yazdım. Orada kendime göre bir şeyler söyledim. Kısaca şunu söylüyorum. Siyer hocası olmak isteyen birisinin mutlaka Arapça bilmesi lazım ve mutlaka bir yabancı dil bilmesi lazım. Ve tabi bütün Siyer kaynaklarını tanımak şartıyla!

Bayram Kanarya: Sayın hocam ülkemizde siyer ve İslam tarihi alanında yapılan çalışmaları nasıl değerlendiriyorsunuz? Akademik camianın çalışmaları nasıl, problemleri nelerdir? Bu anlamda özellikle İslam tarihçilerinin hangi konulara ve nasıl bir yöntemle eğilmelerini tavsiye edersiniz?

İhsan Süreyya Sırma: Ben tabi kimseyi itham etmek istemiyorum. Yalnız bütün alanlarda Türkiye'de ilim ilim için yapılmıyor. Tez için yapılıyor çalışmalar. Yani üniversite hocası olayım şu olayım bu olayım. Böyle ilim olmaz. Bir örnek vereyim. Bizden önce Fransa'ya giden bir abi vardı İslam tarihinde benim gibi. Doktor oldu işte öyle böyle. Fransa'da bir tabir var: Bon pour l'Orient!.. yani şark için iyi, "nasıl olsa gidip kitaplarımı okutacak" zihniyetiyle verilen doktoralar! İşte böyle birisi doktor olunca, bana dedi ki: "Süreyya! Senin Fransız arkadaşların çok. Ben doktor oldum kitaplarımı satacağım bana yardım et". "Abi” dedim "kitap satılır mı ya? "ben doktor oldum bitti falan”. Ben kendisine, “abi ben kitap satmam kitap alırım!” dedim. Sonra o Türkiye'ye geldi profesör oldu. Yani bir tane kitap yazmadı. İşte Türkiye de bu.

Bayram Kanarya: Hocam batıda hadis ve siyer ile ilgili çalışmaları nasıl değerlendiriyorsunuz. Bu bağlamda oryantalistlerin çalışmaları ve bakış açıları ile ilgili neler söylemek istersiniz?

İhsan Süreyya Sırma: Şimdi efendim oryantalistler ne yaparsa haklıdırlar, niye? Yılanın veya akrebin görevi nedir: sokmak. Adam diyor ki "eğer akıllıysan sen de karşıma çık". Hiç çekinmeden söylüyorum dün akşam konferansta da söyledim Hakkari'de. Kardeşim İslam Ansiklopedisi diye bir şey var gördünüz mü? Milli Eğitim Bakanlığı basmış, Diyanetinkini demiyorum. Yüz sene önce Hollanda'da oryantalistler 
yaptı. Türkler veya Araplar hiçbir şey yapmadılar. Ama onlar dediler ki "isterseniz tercüme edebilirsiniz. Hatta bazı maddeleri yeniden yazabilirsiniz. $\mathrm{Bu}$ arada ben Erzurum'dayken birkaç madde istediler; yazmaz olaydım. Ondan sonra o zaman böyle imkânlar yok. Basılınca, benim makalem mi değil mi belli değil, kendileri kuşa çevirmişler ansiklopedinin yani oryantalistlerin Türkiye'deki temsilcileri! Sansürlemişler ve istedikleri gibi ilave yapmışlar. Bir daha yazmadım. O daha yeni bitti Milli Eğitime vermişler tercüme hakkını. O arada bir Diyanet Ansiklopedisi başladı sonra baktım ki bir temsilci geldi Erzurum'a. Dedi ki "Diyanet olarak yeni bir ansiklopedi çıkaracağız; sizlerden de madde istiyoruz. O sıra ben dedim ki "maddeler üzerinde oynayacak mısınız?". Dedi ki “tabi oynayacağız, istediğimizi çıkaracağız.” O zaman "tamam devam edin ben göndermiyorum" dedim ve göndermedim. Ama ben orada açıç̧a umumi söyledim. Müdahale olacaksa yazmıyorum ve yazmadım! Ondan sonra bastılar devam ediyor. Bu ansiklopedi de acemice hazırlanan bir Türk İslam Ansiklopesidir, İslam ansiklopedisi değil! adı öyle ama. Nedenini biliyorsunuz. Türkiye'deki kavmiyetçilikten. Bu kadar açık söyledim.

Bayram Kanarya: Hocam, siret-i nebeviyi anlatan çok sayıda kitap bulunmaktadır. Kur'an'ın nüzul kronolojisini merkeze alarak hadis ve siyer ilimlerinin müdevvenatından yararlanmak suretiyle yeni bir siyer çalışmasına ihtiyaç var mıdır sizce?

İhsan Süreyya Sırma: Bence gerek yok. Bizim selefimiz onları yapmış. Yani ciltlerce bu konuda kitaplar var. Yeni ne yapılabilir, hiçbir şey. Yeter ki içine kavmiyet girmesin! Maalesef Müslümanların tamamı bakın istisna göstermiyorum şimdi İslam'dan önce kavmiyetlerini konuşuyorlar. Kavmiyetçi bir gözle bakıyorlar ilme ve böylece İslam aleminin ne perişan halde olduğunu görüyorsunuz!

Bayram Kanarya: Sayın hocam, yaklaşık dört yıl Siirt üniversitesi ilahiyat fakültesi dekanlığı yaptınız. Ayrıca hem doğu hem de batı üniversitelerinde görev yaptınız. Gerek akademik ve gerekse sosyal ve ekonomik imkânlar açısından bir mukayese yapabilir misiniz?

İhsan Süreyya Sırma: Bir mukayese şöyle. Hakikaten Batı'da eğer birinde bir cevher görüyorlarsa adama her türlü imkânı veriyorlar. Fakat bizim memlekette Türkiye'de fazla imkân verilmiyor ve maalesef bütün İslam dünyasında ilme ideolojik olarak bakılıyor, ilmi olarak bakılmıyor. Onun için ben bir şey beklemiyorum. Doktora, doçentlik tez yaptı, halas! Bitti. Ondan sonra ne yapıyor, hiç. Bir de bir şey daha ilave edeyim. Yeni bir akım başladı. Farklı gözükmek için ortaya yeni tezler koyuyorlar. Peygamber Efendimizi tenkit etme cüreti gösteriyor bazı meslektaşlar. Sünneti eleştiriyorlar. Sünneti kabul etmeme yoluna gidiyorlar. Bu yapılanlar Sünnete, Peygamber'e, İslam'a ihanettir. Bunu da söylemiş olayım. İnşallah sansür uygulamazsinız.

\section{Bayram Kanarya: Hocam hayır sansür uygulamayacağız.}

İhsan Süreyya Sırma: Olursa da ben güzel bir makale hazırlarım sizin hakkınızda. 
Bayram Kanarya: Sayın hocam bugün neredeyse her üniversitenin olduğu ilde bir ilahiyat fakültesi mevcuttur. Bunun yanı sıra bazı özel üniversitelerde de ilahiyat fakülteleri açılmıştır. Bu kadar çok sayıda ilahiyat fakültesine sizce ihtiyaç var mıdır ayrıca bu sayısal çoğunluk beraberinde ne tür yeni sorunlar getirmiştir?

İhsan Süreyya Sırma: Ben şahsen; tabi bize sormuyorlar ki. Ben bu kadar ilahiyata ihtiyaç görmüyorum. Bizim zamanımızda üç dört tane ilahiyat vardı; çok daha kaliteliydiler. Erzurum İslami İlimler Fakültesi çok muazzamdı. Şimdi oraya buraya ilahiyat açıyorlar. Yardımcı doçentlerle idare ediyorlar. Bir doçent yok, profesör yok ve kalite düşük. Maalesef Batı böyle değil! Diyorum ki bir ilahiyatçı, bir ilahiyat profesörü, çağrıldığı konferansta, sempozyumda hadi batı dillerini bırakalım, hiç olmazsa Arapça bir tebliğ sunabilmeli. Maalesef kalite çok düştü.

Bayram Kanarya: Çözüm?

İhsan Süreyya Sırma: Çözüm bende değil ki. Ben bunları kapatalım demiyorum, çünkü açılmış. Ama diyorum ki eleman alınca Allah'tan yana olalım, tanıdıktan yana olmayalım ve kabiliyetli olmayanı almayalım. Dil bilmeyeni, Arapça bilmeyeni veya bir Batı dili bilmeyeni almayalım. Kur'an'ı açmamış olanı almayalım. Eğer bu kıstasları uygularsak zannediyorum düzelir.

Bayram Kanarya: Sayın hocam, elli yıla yakındır Türkiye'de konferanslar vermekte, sempozyumlara katılmaktasınız. Bu süre zarfında sürekli halk ile iç içe bulundunuz. Onların hissiyatını dinlediniz. Bu zaman içerisinde olup bitenlere dair neler söyleyebilirsiniz?

İhsan Süreyya Sırma: Ben şöyle diyorum. Evet Türkiye'de ve yurt dışında çok konferanslara gittim. Haftaya inşallah Cezayir'e gideceğim. Hiçbir zaman bildiğimi değiştirip konuşmadım. İlim ne diyorsa o. Hiç kimseyi memnun etmek için de konuşmadım. Ama maalesef "zülfüyâr" diye bir tabir var Türkçede. Başka dilde yok. Zülfüyâre dokunmamak için "kale fulan kale fulan" bitti. Maza tekulu ente, sen ne diyorsun? Bir insan, bir ilahiyatçı veya bir ilim adamı bir görüşü olabilmeli. Yoksa siradan bir öğretmendir.

Bayram Kanarya: Sayın hocam, tarihi süreçlerde belli dönemlerde farklı inanç ve toplumların dünyaya egemen oldukları bilinen bir husustur. Günümüzün Müslüman devlet ve toplumlarının içinde bulundukları vahim durumu dikkate alarak sizce Müslümanların dünyaya söyleyebilecekleri sözleri kaldı mı, modern dönem Müslüman ahlakı ile ilgili neler söylemek istersiniz?

İhsan Süreyya Sırma: Müslümanların dünyaya söyledikleri şöyle bir sözleri var: Diyorlar ki “biz İslam'ı terk ettik. Ey Avrupalılar sevinin, çünkü biz Kur'an'ı terk ettik, Sünneti terk ettik elhamdulillah birbirimizi öldürüp duruyoruz." Ben Malezya'dan Fas'a kadar bütün İslam dünyasını gezdim. Müslümanlar sadece birbirlerini öldürüyorlar ve burada benim bir görüşüm var. Diyorum ki iki ihtimal var ve bununla bitiriyorum, çünkü geç kaldım. İki ihtimal var: Müslümanlar niye birbirini öldürüyor. Bizim coğrafya başta olmak üzere Suriye'yi görüyorsunuz. Irak’1 görüyorsunuz her taraf kan gölü ve göllerin akıntısı Müslüman kanı. İki ihtimal var: ya 
bu birbirlerini öldürenler Müslüman değil. Ya da Müslümandırlar ama İslam'ın ne olduğunu bilmiyorlar. Ve daha acısı; ya da İslam yanlış bir din. İslam doğru olduğuna göre bugün kendilerine Müslümanım deyip savaşarak milliyetçilik yapanlar Müslümanlıkla hiçbir alakaları yok. Resûlullah (s.a.s) bizi görse "Yahu bu kürtçü, bu türkçü bu arapçı bu irancı deyip, hepimizden yüz çevirir!" Ve diyecek ki; "Allah teala bana böyle bir din göndermedi. Size, "la fadle li arabiyyin 'ala a'cemiyyin, ve lâ li a'cemiyin 'ala 'arabiyyin illâ bit'takva' demedim mi? Şimdi kalkmış, Müslümanlık adına, birbirinize üstünlük taslıyorsunuz!

Yani Arab'ın Arap olmayana üstünlüğü olmadığı gibi, Arap olmayanın da Arab'a üstünlüğü yoktur! Şimdi Müslümanlar dağlarına, "ne mutlu Türküm diyene", "bijî Kurdistan", "ümmetun arabiyyetun hâlide" vs. şeklinde, ırkî yazıyorlar. Ondan sonra beriki fars beriki bilmem ne. Milliyetçi olmuş gitmişiz. Bu milliyetçilik Müslümanlar arasında olduğu müddetçe Müslümanların kurtuluşu diye bir şey olamaz! Her gün İslam'dan daha çok uzaklaşıyorlar. Vesselam...

Bayram Kanarya: Akademik hayatınız boyunca yaptığınız gözlemleri dikkate alarak, ülkemizdeki akademisyenlerin yeterli donanıma sahip olduklarını söyleyebilir misiniz?

İhsan Süreyya Sırma: Yukarıda bu konulara yeteri kadar değindik! liyakat!

Bayram Kanarya: Akademik yaşamınız boyunca İslami düşüncenin toplumda yerleşmesi ve buna göre bir hayatın tesisi için mücadele verdiniz, bu çerçevede Türkiye'de gitmediğiniz yer kalmadı denilebilir. Bundan otuz yıl önceki Türkiye toplumunun dine yaklaşım biçimi ile bu günkü yaklaşımını değerlendirebilir misiniz?

İhsan Süreyya Sırma: O zamanlar imkân az, samimiyet daha fazlaydı.

Bayram Kanarya: Deizmin yaygınlaştığını düşünüyor musunuz? İlahiyat camiası olarak ne tür önlemler alınabilir?

İhsan Süreyya Sırma: İlahiyatçılar, "farklı görünmek" için değil, Kur'an ve Sahih Sünnet'e göre İslâm'ı anlatırlarsa, bu gibi sapık akımlar kendilerine zemin bulamazlar!

Bayram Kanarya: Hocam çok sayıda kitabınız var. Sizce okurlar nezdinde en etkili olan eseriniz/eserleriniz nelerdir? Özellikle Mekke Dönemi ile Medine Dönemi isimli kitaplarınız gençler üzerinde önemli bir etki bıraktığı görülüyor?

İhsan Süreyya Sırma: Gençler son yazdığımız "Müslümanlarda Yanlış Din Anlayışları" kitabımı okurlarsa iyi olur inşallah!

Bayram Kanarya: Hocam çok zengin bir kütüphaneye sahip idiniz. Kütüphanenizin serencamını bize anlatabilir misiniz?

İhsan Süreyya Sırma: O çok sevdiğim bütün kitaplarımı Siirt İlâhiyat Fakültesi Kitaplığına vakfettim.

Bayram Kanarya: Hocam çok teşekkür eder, saygılar sunarız.

İhsan Süreyya Sırma: Ben teşekkür ederim. Allah razı olsun. 